\title{
Predictor of Instant Messaging Use among Students for Academic Purpose
}

\author{
https://doi.org/10.3991/ijim.v14i15.15155
}

\author{
Nur Ain Nabilah Mohd Roslan ${ }^{\bowtie}$, Ahmad Fauzi Mohd Ayub, Norliza Ghazali \\ Universiti Putra Malaysia, Serdang, Malaysia \\ aainroslanegmail.com
}

\begin{abstract}
This study was carried out to identify the predictors of instant messaging use for academic purposes among undergraduates at Faculty of Educational Studies in Universiti Putra Malaysia (UPM). Predictors studied were perceived usefulness, perceived ease of use, perceived enjoyment, perceived convenience, attitude toward use and behavior intention to use instant messaging for academic purposes. A total of 285 samples were selected from undergraduates. Data were collected in a quantitative manner using a questionnaire. The inferential statistic confirmed the significant positive relationship between perceived usefulness, perceived ease of use, perceived enjoyment, perceived convenience, attitude toward use and behavior intention with the use of instant messaging for academic purposes. All relationship was identified as moderate. Also, the multiple linear regressions analysis was used to identify predictors of six independent variables that contributed towards the use of instant messaging. Finally, the results showed the predictors of instant messaging use for academic purposes amongst students were the perceived usefulness, perceived convenience and attitude towards the use of instant messaging. The study indicated that when students feel by using the instant messaging is useful and convenience to them, they will use it. Besides that, positive attitudes towards using instant messaging is among critical factor for the students to use it. This finding further suggests that students in general positively view of instant messaging as a useful tool that supports them in communicating between peers and lecturers. This further suggests that instant messaging platforms are likely to have a positive perception and students feel pleased to use instant messaging as tools of communication.
\end{abstract}

Keywords - Instant messaging, use of Instant messaging for academic purpose, technology acceptance model.

\section{Introduction}

Smartphones have integrated completely into students' life. Students usually have their smartphones with them all the time since it offers many communications features including calling, texting, chatting, and access to social media [1]. Every smartphone comes with mobile instant messaging built-in apps and a digital store with an unlimited supply of different applications. Although mobile instant messaging applications such as WhatsApp, Telegram, WeChat, etc. is a comparatively new category of social media 
tools, it has become an inseparable part of people's lives, especially the younger generations. Apart from sending and receiving messages to and from individuals or groups, instant messaging includes a variety of functions, such as text messages, attached images, audio, video, and links to web addresses [2]. Instant messaging has been used as a tool by university students to convey information among them. Many students use instant messaging as communication tools to support their learning [3]. Students start using instant messaging to conduct online discussions for information sharing activities with students and instructors [4,5]. As higher education institution integrate technology into the classroom curriculum to improve the efficiency of academic standard, university students have adopted new tools in their learning to construct knowledge [6, 7].

Although that instant messaging has its advantages to its users, we need to explore the students' acceptance of instant messaging as a tool of communication between them in tertiary education [8]. It appears that students from Malaysia especially from urban areas have a high level of use of instant messaging. According to [9] Zulkefly and Baharudin (2009) [9], students in Malaysia spend on average 5.98 hours for mobile phone use in a day and the features often used by students were text messaging. This shows that most students have installed instant messaging applications in their smartphones [10]. However, there is a big question if these students are capable to utilize the instant messaging applications. To address this gap, the predictors of the use of instant messaging for the academic purposes among students should be identified. Perceived usefulness, perceived ease of use, perceived enjoyment, perceived convenience, attitude toward use and behaviour intention are important predictors of instant messaging for academic purposes. The purpose of this current research is to explore the use of instant messaging by students for academic purposes in higher education.

Since the year of 2000, many ICT tools are applied in Malaysian schools to support the teaching and learning of various subjects $[11,12]$. The quality of teaching is enhancing when the effective implementation of ICT and will promote positive communication between instructors and learners [13]. Teachers and students made a necessary adjustment in their day by day learning process to adapt to the latest advancement within the field of ICT [14]. The study by [15] to assess Malaysian teachers' levels of ICT integration as well as its impact on teaching and learning the teachers showed that ICT integration is still at a low level. While, ICT is perceived to bring a positive impact on their teaching and also perceived to affect their students' learning. Higher education students in Malaysia have great exposure to a variety of ICT resources to support teaching and learning. Mobile applications like chatting apps, email, social media apps such Facebook, Twitter, Instagram is commonly used by students. A study by [16] shows that university students tend to use social media to communicate to discuss topics relating to their studies with peers. This also supported by a study by [17] revealed that multimedia technology has been invested in Malaysian tertiary education has improve the both teaching and learning fields. This represents the positive and advance of ICT integration among higher education students in Malaysia. 


\subsection{Instant messaging in education}

Instant messaging is free and easy to use and offers several benefits to its users. It has been used for over a decade that enables users to communicate on the internet with others in real-time [18]. Instant messaging enables online collaboration and communication and promotes students' learning performance [19, 20]. Students and instructors can engage in meaningful social interaction. A study by [21] reported that using instant messaging a learning tool benefit to both peers and instructor as it is helpful in increasing their social interactivity. Chat groups are used for four main purposes: communicating with peers, creating social interactivity, a learning platform and encouraging conversation and sharing among students [2]. A study conducted by [22] revealed six specific ways in which instant messaging was used in education: journaling, dialogic, trans-missive, constructionist with peer feedback, helpline, and assessment. Instant messaging can be a serious tool to support teaching and learning. Yue (2015) [23] explored the perception and engagement in using instant messaging for a group of students in higher education discovered that student have high engagement towards academic projects related in the social application. The individuals' perception of the usefulness of instant messaging is an additional attribute that may increase their academic success in the learning environment. Research conducted by [24] among student nurses found that students used instant messaging quite frequently and they perceived that this platform strongly enhanced their communication with other students.

\subsection{Use of instant messaging for academic purpose}

Previous studies examined the use of Instant Messaging (IM) to facilitate learning. A study by [25] revealed how students were able to ask questions during the learning process via instant messaging after school hours to receive academic support in mathematics. The teacher has better chances to know the students and could help in a relevant way with a personal connection between teacher and students. Research by [26] that involved 115 university students shows that the students make good and ample use of social media and instant messaging applications for university-related work and facilitating their learning and interactions with students and instructors. The integration of instant massaging in education reveals that features contribute to the learning process; active participation in class, encouraging collaborative learning, learning any time any place, and informal communication, are common to all the platforms [2]. Still, research reveals that these tools aren't widely implemented.

This study is to determine the predictor that the students use instant messaging for academic-related purposes. Based on the theoretical framework of the study, there are six variables that have been chosen as the predictor to the instant messaging use. These predictors are the perceived usefulness, perceived ease of use, perceived enjoyment, perceived convenience, attitude toward use and behavior intention. The conceptual framework of the study is presented in Figure 1. 


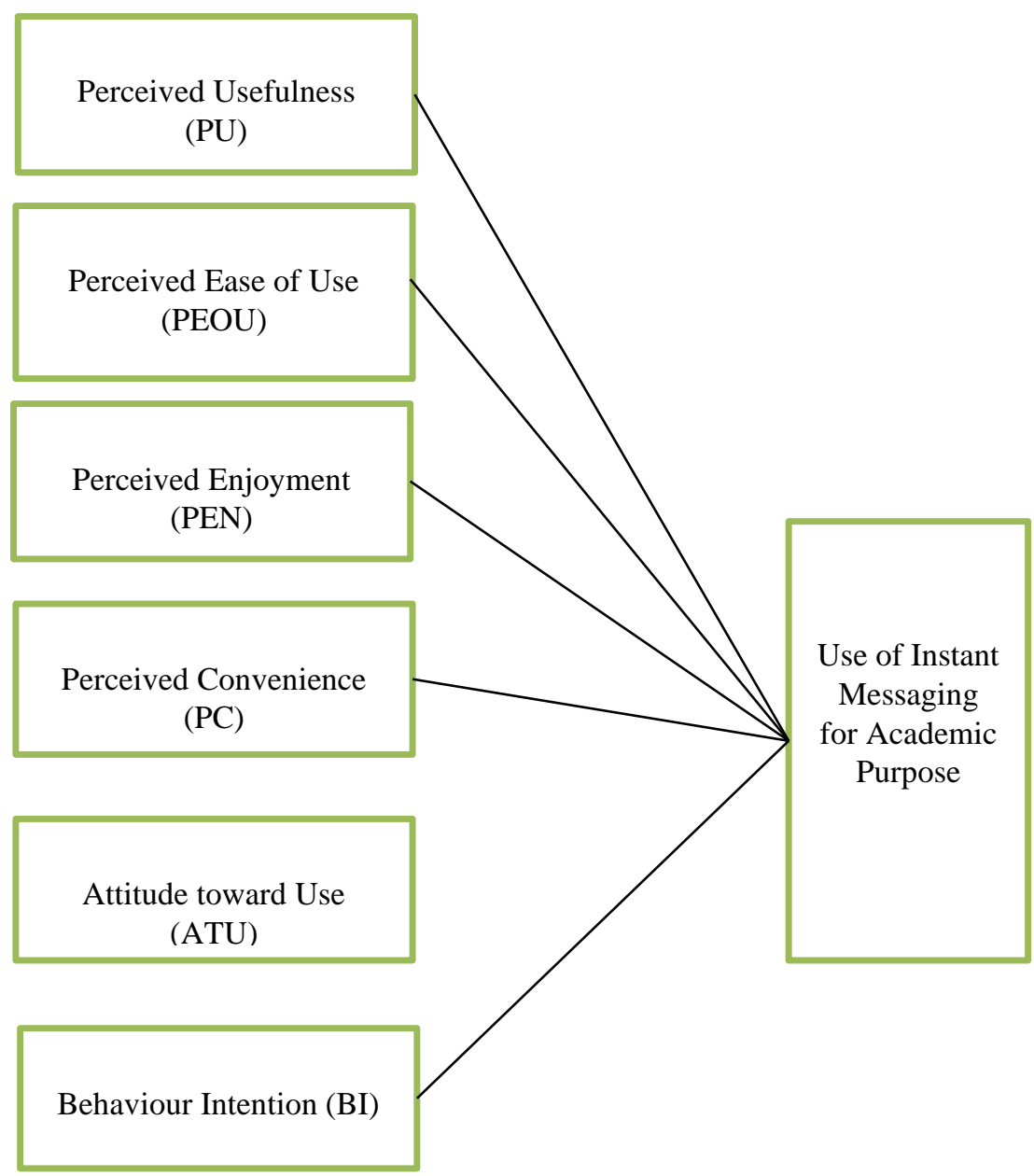

Fig. 1. Conceptual Framework

Figure 1 shows the conceptual framework developed in correspondence with the objective of this study is based on [27] Davis's Technology Acceptance Model (TAM) (1989) with the addition of two other variables which are perceived enjoyment and perceived convenience. These variables are important predictors in explaining the use of instant messaging for academic purposes. As a result, this conceptual framework suggested the model of this study to determine the predictors of the use of instant messaging. It demonstrated students' perceived usefulness, perceived ease of use, perceived enjoyment, perceived convenience, attitude toward use and behaviour intention could probably predict the use of instant messaging for academic purpose among university students. 


\section{$2 \quad$ Research Objectives}

a) To determine students' perceived usefulness, perceived ease of use, perceived enjoyment, perceived convenience, attitude towards use, behavior intention and the use of instant messaging for academic purpose.

b) To determine the relationship between students' perceived ease of use, perceived usefulness, perceived enjoyment, perceived convenience, attitude toward use, behavior intention with actual use of instant messaging for academic purpose.

c) To determine predictors of the use of instant messaging for academic purposes.

\section{$3 \quad$ Methodology}

This study employed the correlational research design to determine the predictors that students use instant messaging for academic purposes. The design was meant among undergraduates at Faculty of Educational Studies, Universiti Putra Malaysia. The population for this study consisted of 1108 undergraduates enrolled in seven programs at the faculty. Cluster sampling was used in this study. In cluster sampling, a sample is randomly selected in the grouping (clusters) rather than individual [28] and a researcher can survey the whole cluster of the population selected at random. The actual sample size obtained for this study is 285 , which is to ensure that a sufficient sample is used in this study.

For data collection, a briefing was given to the respondents before distributing the questionnaire. The questionnaire was collected once the students had completed it. The questionnaire consisted of nine parts: (A-I). Part A gathered demographic information of the respondent. In sections, B-H of the questionnaire were used a 5-point Likert scale that refers to 'strongly disagree, disagree, neutral, agree and strongly agree'. Part I is an open-ended question that consists two questions to determine the students' opinion on the use of instant messaging in teaching and learning at university. The pilot test was carried out using 30 students from different semesters of study at the faculty. The questionnaire was collected from the 30 students and data were entered into SPSS to perform the Cronbach Alpha reliability test.

\section{$4 \quad$ Findings}

Most of the respondents involved in this study were females which is 250 respondents $(87.7 \%)$. In terms of program studied, it's nearly equal where the percentage of respondents is $10 \%-15 \%$ except respondents from physical science. The overall mean for time spent on IM was 8.46 hours per day $(\mathrm{SD}=4.86)$ and most of them spend 1 to 6 hours per day on IM. 
Table 1. Demographic Information

\begin{tabular}{|l|l|c|c|}
\hline & & $\mathbf{N}$ & \% \\
\hline Gender & Male & 35 & 12.3 \\
\hline & Female & 250 & 87.7 \\
\hline Respondents & Agricultural Science & 35 & 12.3 \\
\hline & Guidance and Counselling & 45 & 15.8 \\
\hline & Home Science & 40 & 14.0 \\
\hline & Human Resource Development & 30 & 19.3 \\
\hline & Physical Science & 55 & 15.5 \\
\hline & $\begin{array}{l}\text { Teaching English as a second } \\
\text { language }\end{array}$ & 44 & 12.6 \\
\hline & $\begin{array}{l}\text { Teaching Malay Language as a } \\
\text { first language }\end{array}$ & 36 & 43.5 \\
\hline Time Spent on IM & 1 to 6 hours & 124 & 40.4 \\
\hline & 7 to 12 hours & 115 & 11.9 \\
\hline & 13 to 18 hours & 34 & 4.2 \\
\hline & 19 to 24 hours & 12 & \\
\hline
\end{tabular}

The first objective of the study was to determine students' perceived usefulness, perceived ease of use, perceived enjoyment, perceived convenience, attitude towards use, behavior intention and the use of instant messaging for academic purposes. In this study, the overall mean of each predictive factor is presented in Table 2. All factors were considered high which greater than 4.0 except behavior intention $(\mathrm{M}=3.62, \mathrm{SD}=$ .3). The highest mean is respondents' perception towards perceived convenience $(\mathrm{M}=$ $4.30, \mathrm{SD}=.52$ ) followed by their attitudes toward the use of IM.

Table 2. Overall Mean for Predictors on the Use of Instant Messaging for Academic Purposes

\begin{tabular}{|l|c|c|}
\hline & Total Mean & Total SD \\
\hline Perceived Usefulness & 4.05 & 0.55 \\
\hline Perceived Ease of Use & 4.16 & 0.55 \\
\hline Perceived Enjoyment & 4.12 & 0.56 \\
\hline Perceived Convenience & 4.30 & 0.52 \\
\hline Attitude toward Use & 4.23 & 0.56 \\
\hline Behavior Intention & 3.62 & 0.30 \\
\hline Use of IM for Academic Purpose & 4.33 & 0.49 \\
\hline
\end{tabular}

The second objective of this study was to determine the relationship between students' perceived ease of use, perceived usefulness, perceived enjoyment, perceived convenience, attitude toward use, behavior intention with the actual use of instant messaging for academic purposes. The relationship between the predictive factors with the use of instant messaging is presented in Table 3. 
Table 3. Relationship between Each Predictor with the Use of Instant Messaging

\begin{tabular}{|l|c|l|}
\hline & Use of IM & \multicolumn{1}{|c|}{ Correlation interpretation } \\
\hline Perceived Usefulness & $0.602^{* *}$ & Moderate positive relationship \\
\hline Perceived Ease of Use & $0.641^{* *}$ & Moderate positive relationship \\
\hline Perceived Enjoyment & $0.603^{* *}$ & Moderate positive relationship \\
\hline Perceived Convenience & $0.604^{* *}$ & Moderate positive relationship \\
\hline Attitude toward Use & $0.655^{* *}$ & Moderate positive relationship \\
\hline Behavior Intention & $0.536^{* *}$ & Moderate positive relationship \\
\hline
\end{tabular}

$* *$ Significant at 0.01

To determine the relationship between students' perceived ease of use, perceived usefulness, perceived enjoyment, perceived convenience, attitude toward use, behavior intention with the actual use of instant messaging for academic purpose, the Pearson correlation was performed using data from each predictive factor of the study. Overall, the analysis showed a significant positive relationship between all the predictive factors and the use of instant messaging. According to [29], all the relationship was identified as moderate.

The third objective of this study is to determine the predictors of the use of instant messaging for academic purposes. Multiple Linear Regression analysis using ENTER method was used to answer this research question. The data obtained has fulfilled the requirements for performing multiple linear regression analyses. To identify the combination of independent variables that became the predictive factors of the use if instant messaging, multiple linear regression analysis was used to determine the significance of relationships and independent variables (predictors) that contributed to the dependent variable (criterion). In this study, the enter method of Multiple Linear Regression was able to explain the variance of use of instant messaging by using perceived usefulness, perceive ease of use, perceived enjoyment, perceived convenience, attitude toward the use and behavior intention.

Table 4. Model Summary

\begin{tabular}{|c|c|c|c|c|}
\hline \multicolumn{4}{|c|}{ Model Summary } \\
\hline Model & $\boldsymbol{R}$ & $\boldsymbol{R}^{2}$ & Adjusted $\boldsymbol{R}^{2}$ & Std. Error of the Estimate \\
\hline 1 & .746 & .557 & .547 & .33013 \\
\hline
\end{tabular}

The following model summary in Table 4 shows that the multiple correlation coefficient $(\mathrm{R})$ obtained was 0.746 using all the predictors simultaneously and the adjusted $\mathrm{R}^{2}$ value obtained was 0.547 . The adjusted $\mathrm{R}^{2}$ value obtained in this study was 0.547 , indicating that the combination of the six variables was able to predict $54.7 \%$ of the variation in the use of instant messaging for academic purposes.

Table 5. ANOVA

\begin{tabular}{|l|c|c|c|c|c|}
\hline \multicolumn{1}{|c|}{ Model } & Sum of Squares & df & Mean Square & F & Sig. \\
\hline \multirow{2}{*}{$\begin{array}{l}\text { Regression } \\
\text { Residual } \\
\text { Total }\end{array}$} & 38.062 & 6 & 6.344 & \multirow{2}{*}{58.207} & \multirow{2}{*}{$.0001^{\text {b }}$} \\
\cline { 2 - 6 } & 30.298 & 278 & .109 & & \\
\cline { 2 - 6 } & 68.360 & 284 & & & \\
\hline
\end{tabular}


Table 5 shows the ANOVA analysis results for the Multiple Linear Regression model. ANOVA, F $(6,278)$ obtained was $58.207(\mathrm{p}=0.001)$ with the p-value smaller than 0.05 was obtained, indicating that the combination of predictors (perceived usefulness, perceived ease of use, perceived enjoyment, perceived convenience, attitude toward use and behavior intention) significantly predicts the dependent variable (use of instant messaging for academic purpose). Table 5 summarises the analysis of variance (ANOVA) output. It can be affirmed that overall, the domains of attitudes employed in this regression model predicted statistics engagement significantly well, with the test statistic, F 4,288) = $73.04(\mathrm{p}<0.05)$. The coefficients of the fitted regression model can be found in Table 6 . It was clear that all four domains of attitudes significantly contributed to the model i.e. all four domains were significant explanatory variables and equally vital to explain students' statistics engagement $(\mathrm{p}<0.05)$.

Table 6. Coefficient Multiple Linear Regression for Use of Instant Messaging

\begin{tabular}{|l|c|c|c|c|c|}
\hline \multicolumn{7}{|c|}{ Use of IM for Academic Purpose } & \multicolumn{2}{c|}{ Sig } \\
\hline \multicolumn{1}{|c|}{ Model } & Unstandardized Coefficients & \multicolumn{2}{c|}{ Standardized Coefficients } \\
\hline \multicolumn{1}{|c|}{ Independent variable } & Beta & Std. Error & Beta & \multicolumn{1}{c|}{ T } & Sig \\
\hline (Constant) & 0.666 & 0.243 & & 2.748 & .006 \\
\hline Perceived Usefulness & 0.115 & 0.056 & .128 & 2.036 & .043 \\
\hline Perceived Ease of Use & 0.128 & 0.069 & .129 & 1.856 & .065 \\
\hline Perceived Enjoyment & 0.081 & 0.055 & .092 & 1.468 & .143 \\
\hline Perceived Convenience & 0.188 & 0.053 & .199 & 3.541 & .000 \\
\hline Attitude toward Use & 0.226 & 0.054 & .259 & 4.168 & .000 \\
\hline Behaviour Intention & 0.158 & 0.086 & .097 & 1.841 & .067 \\
\hline
\end{tabular}

By referring to Table 6, the statistical analysis showed that attitude toward the use of instant messaging had a stronger contribution to the use of instant messaging with a beta value $(\beta)$ of $0.226(t=4.168)$ compared to other independent variables. To fulfill the final objective in this study, to identify the predictors of the use of instant messaging, Beta $(\beta)$ values have been referred to identify the predictor variables that contribute to the use of instant messaging for academic purposes. Based on these values it can be concluded that the attitude toward use variable is the most important predictor of the students' use of instant messaging. It demonstrates the perceived enjoyment contributing the least amount to predict the students' use of instant messaging for academic purposes amongst students of Faculty of Educational Studies, UPM. The independent variables make a significant unique contribution to the prediction use of instant messaging for academic purposes, $\left[\mathrm{F}\left(6,278=58.207, p=0.0001, \mathrm{R}^{2}=0.547\right]\right.$ and the attitude toward use is the strongest predictors toward the use of instant messaging for academic purpose compared to other variables.

\section{Discussions}

The findings from this study revealed that the respondents agreed that the use of instant messaging enables students to manage their academic requirements by communicating with peers using this communication channel. Tang and Hew (2017) [22] 
who also reports that students feel the instant messaging is useful in the learning process in education. The analysis also shows that students feel an interaction in instant messaging is clear and understandable. With the simple and ease of chatting features offered by the instant messaging application, it is easy to acquire the skill in using instant messaging. This study also is in line with the study by [30] who reports that usability affects the satisfaction to use the mobile instantly. An instant messaging platform offers the student learning activities to be easier and meaningful. The analysis also shows that students feel the instant messaging platforms offered them a more entertaining and joyful learning environment for their communication. For instance, students can exchange images of learning materials, recorded voices and graphics using instant messaging. This has made an academic discussion lively since student's expression can be shared using animated graphic representation such as emoji and gif. However, the use of the instant messaging amongst these students should also be monitored from time to time as various news is received regarding the negative aspects of social application usage [31]. They tend to spend on the application too long that cause an unproductive lifestyle. If these attitudes are not monitored and controlled, it can lead to a negative impact such as wasting time which in turn degrading academic performance. In this study, the majority of students said they had apex experience (i.e. good, wise, pleasant, and beneficial) in learning compared to the bad experiences of using instant messaging. Based on findings in the open-ended questionnaire section, students expressed that they prefer face-to-face communication during academic lessons especially in communicating with lecturers. Overall, the researchers can conclude the students expressed that it is worth using instant messaging for academic purposes for certain situational environments (i.e. after lecturing sessions and diverse locations during discussion sessions).

The relationship between perceived usefulness and the use of instant messaging is moderate may be due to factors that instant messaging is known to serve as a communication tool but not as the learning tool has led to a moderate relationship between perceived usefulness and the students' use of instant messaging for academic purpose. This should be nurtured by explaining and expanding comprehensively on how instant messaging can assists students so that they understand that instant messaging can help improve their performance in academics too by engaging with other students. The relationship between perceived ease of use with the use of instant messaging is moderate as it may be because factors such as the instant messaging application used fewer features of usability, low capability in operating technology and limited access to internet access due to incomplete internet infrastructure at their faculty and residence. Based on the respondent's response in the open-ended section, it is impossible to use instant messaging especially when there is low or no wireless fidelity (Wi-Fi) accessibility. The students should be guided so that they do not have the wrong perception of instant messaging is a technology that is challenging to use due to no broadband or wide coverages which in turn this platform does not benefit them. Past studies by [3] that examine the relationship between these variables also show significant relationships when people feel instant messaging is easy for them to handle then they have a desire to use them in the future. The relationship between perceived enjoyment with the use of instant messaging is moderate as it may be because factors such as the instant messaging applica- 
tion getting boring and unpleasant. The rate of adoption by technology can be represented by using technology during a specific period of time. Therefore, the students will reach at a certain time when they start to feel boring using instant messaging. Past studies by [32] also show significant relationships that when people feel the instant messaging is enjoyable for them in an academic environment to enhance students' learning accomplishments. The relationship between perceived convenience with the use of instant messaging is moderate as it is because of factors such as accessibility and disturbing to some people. Instant messaging is a real-time communication in which the dispersion of information takes place very quickly. However, for this to occur, both parties need to be actively available. If the students are not connected to the application while others are having the discussion, the person tends to miss out on what is being discussed. Furthermore, instant messaging can be accessed anytime, but sometimes people tend to overlook the practice of not disturbing people especially lecturers beyond office hours. Therefore, the students can only reach the application at the time when it is appropriate. Studies by [33] also found that attitude had a relationship with the respondent's desire to use the technology studied which similar to the current study. It demonstrates the attitude toward use plays an important role in influencing the actual use of technology. This study suggests that attitudes toward use is an important element to be studied in determining the use of instant messaging. Students with a high attitude tend to respond a lot than students with low attitude toward instant messaging. Currently, there is another option for applications that serves as real-time communication tools such as video conferences. With more advance technology serve by other applications, the need to use instant messaging is debatable. Students may opt for other applications to communicate with peers and lecturers. Therefore, instructors can always use any other way and integrate it with instant messaging to create an interactive learning environment. This approach can help students to improve their behavior intention on the use of instant messaging for academic purposes in the future. Similar studies have also been carried out on the study of the relationship between behavioral intention toward the use of such technology. Among them are Ajjan et al. (2014) [34], Isiyaku et al.,(2017) [35], and Baleghi-Zaideh et. al (2017) [36] also found that behavioral intention had a relationship with the actual use of technology studied. When behavior intention increases with the use of technology then the individual's perceived for technology will also increase. Therefore, these students need to be trained to integrate instant messaging into daily activities related to learning. Overall, students believe that it is worth it to use instant messaging for academic purposes.

However, based on the multiple linear regression analysis obtained in this study three variables that are not significant. The three variables not influencing the use of instant messaging for academic purposes in this study are perceived ease of use, perceived enjoyment and behavior intention of using instant messaging. The result is may due to the factors miscommunication, addiction to device and less face to face interaction. This can cause serious problems especially during classes. Majority lecturer facing a problem whereby students spending most of their time in the lecture hall by staring at their phone which in turn distress the learning session hence affecting the academic performance. 


\section{Conclusion}

This study was done to determine the predictor of the use of instant messaging for academic purposes. The findings of this study do not provide information about the features of instant messaging application but they give insights into students' perception of the acceptance of instant messaging. To conclude this, the current study has responded to a call for more research on students' acceptance of using instant messaging for academic purpose and contributed to the emerging studies on blended learning. The findings suggested a significant relationship between perceived usefulness, perceived convenience and attitude toward the use of instant messaging for academic purposes. As indicated earlier on, perceived usefulness, perceived convenience and attitude toward use significantly predict the use of instant messaging for academic purposes. This finding further suggests that students in general positively view of instant messaging as a useful tool that supports them in communicating between peers and lecturers. This further suggests that instant messaging platforms are likely to have a positive perception and students feel pleased to use instant messaging as tools of communication.

\section{$7 \quad$ References}

[1] Smale, M. A., \& Regalado, M. (2016). Digital Technology as Affordance and Barrier in Higher Education. Boston: Palgrave Macmillan, Cham.

[2] Bouhnik, D., \& Deshen, M. (2014). WhatsApp goes to school: Mobile Instant Messaging between teachers and students. Journal of Information Technology Education: Research, 13, 217-231. https://doi.org/10.28945/2051

[3] Lauricella, S., \& Kay, R. (2013). Exploring the use of text and instant messaging in higher education classrooms. Research in Learning Technology, 21(2013), 1 - 17. Doi: 10.3402/ rlt.v21i0.19061. https://doi.org/10.3402/rlt.v21i0.19061

[4] Susilo, A. (2014). Exploring Facebook and WhatsApp as Supporting Social Network Applications for English Learning in Higher Education. In Teaching and Learning in The 21st Century: Challenges for Lecturers and Teachers. Conferences on Professional Development in Edcuation (pp 10-24). Open University Malaysia Press.

[5] Ghadirian, H., Salehi, K. \& Ayub, A.F.M. (2018). Social annotation tools in higher education: a preliminary systematic review. Int. J. Learning Technology, 13, 130-162. https://doi. org/10.1504/ijlt.2018.092096

[6] Dumpit, D. Z., \& Fernandez, C. J. (2017). Analysis of the use of social media in Higher Education Institutions (HEIs) using the Technology Acceptance Model. International Journal of Education Technolog in Higher Education, 14, 1-16. https://doi.org/10.1186/s41239$\underline{017-0045-2}$

[7] Daneji, A.A., Ayub, A.F.M., \& Khambari, M.N.M (2019). The effects of perceived usefulness, confirmation and satisfaction on continuance intention in using massive open online course (MOOC). Knowledge Management \& E-Learning, 11, 201-214. https://doi.org/10. 34105/i.kmel.2019.11.010

[8] Ramana, A., Sani, R. M., \& Kaur, P. (2014). Facebook as a Collaborative and Communication Tool: A Study of Secondary School Students in Malaysia. Social and Behavioral Sciences, 155(6), 141-146. https://doi.org/10.1016/j.sbspro.2014.10.270

[9] Zulkefly, S. N., \& Baharudin, R. (2009). Mobile phone use amongst students in a university in Malysia: its correlates and relationship to psychological health. European Journal of Scientific Research, 37(2), 206-218. 
[10] Amanullah, A. N. A. A., and Ali, N. A. M. (2014). The most favorable mobile messaging apps among IIUM students.International Journal of Science and Research,3: 2497-2502.

[11] Lau, B., \& Chia, H. (2008). Exploring the Extent of ICT Adoption among Secondary Teachers in Malaysia. International Journal of Computing and ICT Research, 2(2). 19-36.

[12] Wong, S.L., Jalil, H.A, Ayub, A.F.M., Bakar, K.A., Tang, S.H. (2008). Teaching a discrete information technology course in a constructivist learning environment: Is it effective for Malaysian pre-service teachers? Internet and Higher Education, 6(2), 193-204 https://doi .org/10.1016/s1096-7516(03)00025-3

[13] Becta. (2003). What the research says about using ICT in Maths. British Educational Communications and Technology Agency (BECTA). http://www.becta.org.uk/page documents/ research/wtrs_maths.pdf.

[14] Lewin, C. \&. McNicol, S. (2015). Supporting the Development of 21st Century Skills through ICT. In Brinda, T., Reynolds, N., Romeike, R., \& Schewill, A. (eds). KEYCIT 2014: Key Competencies in Informatics and ICT. (pp 181-198). University of Potsdam, Germany.

[15] Umar, I. N., \& Hassan, A. S. A. (2015). Malaysian teachers' levels of ICT integration and its perceived impact on teaching and learning. Procedia-Social and Behavioral Sciences, 197. (2015), 2015-2021. https://doi.org/10.1016/j.sbspro.2015.07.586

[16] Reddy, V.P. (2014). The Influence of Social Media on International Students' Choice of University and Course. Queensland University of Technology.

[17] Mansor, N., Ibrahim, S., Ahmad, N., Salam, W., Zulkanain, M., \& Jamaluddin, H. (2014). Social Media in ESL Classroom: Exploring the Impact on Language Learning. Journal of Business and Social Development, 2(1). 14-18.

[18] Grinter, R. E., \& Palen, L. (2002). Instant Messaging in Teen Life. in Churchill, E. F., McCarthy, J., Neuwirth, C., \& Rodden, T. (Eds.). CSCW '02, Proceedings of the 2002 ACM conference on Computer supported cooperative work (pp. 21-30). Association for Computing Machinery. https://doi.org/10.1145/587078.587082

[19] Barhoumi, C. (2015). The effectiveness of WhatsApp mobile learning activities guided by activity theory on students' knowledge management. Journal of Contemporary Educational Technology, 6, 221-238. https://doi.org/10.30935/cedtech/6151

[20] Ghadirian, H. \& Ayub, A.F.M. (2017). Peer moderation of asynchronous online discussions: An exploratory study of peer e-moderating behaviour. Australasian Journal of Educational Technology. 33, 1 - 18. https://doi.org/10.14742/ajet.2882

[21] Malecela, I. O. (2016). Whatsapp among Postgraduate Students Kulliyyah of Education, International Islamic University Malaysia. International Journal of Advanced Engineering Research and Science(IJAERS), 2(10), 126-137. https://doi.org/10.22161/ijaers/ $\underline{310.21}$

[22] Tang, Y., \& Hew, K. F. (2017). Examining Student Participation and Perception of Mobile Instant Messaging: An Exploratory Study. International Journal of Learning and Teaching, 4(3), 264-271. https://doi.org/10.18178/ijlt.3.4.264-271

[23] Yue F. (2015) Student Engagement in the Use of Instant Messaging Communication in Flexible Education. In: Li K.C., Wong TL., Cheung S.K.S., Lam J., Ng K.K. (eds) Technology in Education. Transforming Educational Practices with Technology. Communications in Computer and Information Science, vol 494. Springer, Berlin, Heidelberg https://doi.org/10 .1007/978-3-662-46158-7_1

[24] Pimmer, C., Brühlmann, F., Odetola, T. D., Dipeolu, O., Gröhbiel, U., \& Ajuwon, A. J. (2018). Instant messaging and nursing students' clinical learning experience. Nurse education today, 64, 119-124. https://doi.org/10.1016/j.nedt.2018.01.034

[25] Mashaua, N., L., \& Mokwena, S., N. (2017). Adoption of Instant Messaging for Mathematics Lessons in Rural Schools, International Electronic Journal of Mathematics Education, 12(3), 447-462. 
[26] Gascón, J. F. G., Mir-Bernal, P., L Crespo, J., Carreras-Alcalde, M., \& Feliu-Roé, L. (2017). Use of social networking sites and Instant Messaging applications for university-related work and studying. Observatorio (OBS*), 11, 17-24. https://doi.org/10.15847/obsobs1132017877

[27] Davis. (1989). Perceived usefulness, perceived ease of use, and user acceptance of information technology. MIS Quaterly, 13, 319-340. https://doi.org/10.2307/249008

[28] Daniel, J. (2011). Sampling essentials: Practical guidelines for making sampling choices. Thousand Oak, California:SAGE publication. https://doi.org/10.4135/9781452 272047

[29] Jackson, S. L. (2011). Research Methods and Statistics: A Critical Thinking Approach, (5th. Ed.). Boston: Cengage Learning.

[30] Oghumaa, A. P., Chang, Y., Fernando, L.-S. C., Park, M.-C., \& Rhod, J. J. (2015). Benefitconfirmation model for post-adoption behavior of mobile instant messaging applications: A comparative analysis of KakaoTalk and Joyn in Korea. Telecommunications Policy, 39(8), 658-677. https://doi.org/10.1016/j.telpol.2015.07.009

[31] Jacobsen, W. C., \& Forste, R. (2011). The wired generation: Academic and social outcomes of electronic media use among university students. Cyberpsychology, Behavior, and Social Networking, 14(5), 275-280. https://doi.org/10.1089/cyber.2010.0135

[32] Soares, A. M. \& Pinho, J. C. (2014) Advertising in online social networks: the role of perceived enjoyment and social influence. Journal of Research in Interactive Marketing, 8(3), 245-263.

[33] Amry, A. B. (2014). The impact of WhatsApp mobile social learning on the achievement and attitudes of female students compared with face to face learning in the classroom. European Scientific Journal, 10, 116-136.

[34] Ajjan, H., Hartshorne, R., Cao, Y. \& Rodriguez, M (2014). Continuance use intention of enterprise instant messaging: A knowledge management perspective. Behaviour and Information Technology. 33(7). 678-692. https://doi.org/10.1080/0144929x.2014.886722.

[35] Isiyaku, D.D., Ayub, A.F.M \& Abdulkadir, S. (2015). Empirical modeling of information communication technology usage behaviour among business education teachers in tertiary colleges of a developing country. South African Journal of Education. 35, 1- 14. https:// doi.org/10.15700/saje.v35n4a1101

[36] Baleghi-Zadeh, S., Ayub, A.F.M., Mahmud, R., \& Daud, S.M. (2017) The influence of system interactivity and technical support on learning management system utilization. Knowledge Management \& E-Learning, 9, 50 - 68. https://doi.org/10.34105/j.kmel. $\underline{2017.09 .004}$

\section{Authors}

Nur Ain Nabilah Mohd Roslan is working in Universiti Putra, Malaysia. Email: aainroslan@gmail.com

Ahmad Fauzi Mohd Ayub, is working in Universiti Putra Malaysia, Serdang, Malaysia

Norliza Ghazali is working in the department of Education Universiti Putra Malaysia, Serdang, Malaysia

Article submitted 2020-04-22. Resubmitted 2020-05-23. Final acceptance 2020-05-24. Final version published as submitted by the authors. 